\title{
El club juvenil como estrategia para la prevención del consumo de drogas y la delincuencia juvenil. Caso Barrancabermeja
}

\section{The youth club as a strategy for the prevention \\ of drug use and juvenile delinquency. Barrancabermeja case \\ O clube juvenil como estratégia de prevenção do uso de drogas e delinquência juvenil. Caso Barrancabermeja}

Fecha de recepción: 2020/0I/30 | Fecha de evaluación: 2021/02/18 | Fecha de aprobación: 2021/02/22

\section{Armando Aguilera-Torrado}

Doctor en Ciencias Sociales, Niñez y Juventud

Docente de la Escuela Superior de Administración Pública Territorial Santander Director del grupo de investigación Centro Regional de Investigaciones Humanas, Sociales y Ambientales, Fundación Reeducativa Profuturo

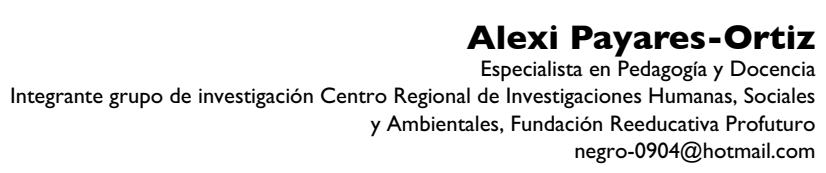

Alexi Payares-Ortiz

Para citar este artículo / To reference this article / Para citar este artigo: Aguilera-Torrado, A. \& Payares-Ortiz, A. (202I). El club juvenil como estrategia para la prevención del consumo de drogas y la delincuencia juvenil. Caso Barrancabermeja. Revista Criminalidad, 63(2), 155-174. https://doi.org//0.4774I//7943108.322

\section{Resumen}

El artículo presenta los resultados de un estudio de caso de tipo descriptivo que se ejecutó en el municipio de Barrancabermeja, departamento de Santander, Colombia. El mismo asumió como objetivo central describir la utilidad que tuvo la aplicación de una estrategia de aprendizaje experiencial (clubes juveniles), como método o maniobra para la prevención del consumo de drogas y la violencia juvenil. El programa se puso en marcha mediante el diseño metodológico de estudio de caso, lo cual permitió sistematizar por 12 meses la experiencia de clubes juveniles que buscaron desarrollar valores, habilidades para la vida y competencias prelaborales en 100 adolescentes o jóvenes en edades entre los 12 y los 21 años de edad, de estrato uno en situación de vulnerabilidad $y$ riesgo frente al consumo de drogas $y$ la delincuencia juvenil. Los resultados del trabajo investigativo revelaron que la implementación de programas preventivos que involucran metodologías experienciales, activas o participativas son una estrategia pedagógica que mantiene motivados a los adolescentes o jóvenes. Igualmente se evidenció que el club juvenil lleva la prevención de consumo de drogas y delincuencia juvenil a un nivel que va más allá de la información, generando procesos de metacognición o reflexión que permiten ejercer las habilidades para la vida. Como conclusión general de la investigación es posible afirmar que las metodologías participativas que involucran la acción/reflexión como principio pedagógico logran un mayor estímulo en los jóvenes y garantizan una mayor expectativa frente al cambio de conductas.

\section{Palabras clave}

Infancia, juventud, consumo de drogas, problemas sociales, infracción (fuente: Tesauro Criminológico - Instituto Interregional de las Naciones Unidas para Investigaciones sobre la Delincuencia y la Justicia - UNICRI). Prevención de delincuencia (fuente: autores). 


\section{Abstract}

The article presents the results of a descriptive case study, which was developed in the Municipality of Barrancabermeja Department of Santander-Colombia. It assumed as a central objective to describe the usefulness of the application of an experiential learning strategy (youth clubs), as a method and / or maneuver for the prevention of drug use and youth violence. The program was developed through the methodological design of a case study, which allowed to systematize for 12 months the experience of development of youth clubs that sought to develop values, life skills and pre-work competence in 100 adolescents and / or young people between the ages of 12 and 21 years, from stratum one in a situation of vulnerability and risk in the face of drug use and juvenile delinquency. The results of the research work revealed that the implementation of preventive programs that involve experienced, active and/or participatory methodologies are a pedagogical strategy that keeps adolescents and/or young people motivated. It was also evidenced that the youth club takes the prevention of drug use and juvenile delinquency to a level that goes beyond information, generating processes of metacognition and / or reflection that allow the exercise of life skills. As a general conclusion of the work, it is possible to affirm that participatory methodologies that involve action/reflection as a pedagogical principle achieve greater motivation in young people and guarantee a greater expectation in the face of behavior change.

\section{Keywords}

Childhood, youth, drug use, social problems, offense. (source: Criminological Thesaurus - United Nations Interregional Crime and Justice Research Institute - UNICRI). Crime prevention (source: author).

\section{Resumo}

O artigo apresenta os resultados de um estudo de caso descritivo, desenvolvido no Departamento de Barrancabermeja do Santander-Colômbia. Assumiu como objetivo central descrever a utilidade da aplicação de uma estratégia de aprendizagem experiencial (clubes juvenis), como método e/ou manobra para a prevenção do uso de drogas e violência juvenil. $O$ programa foi desenvolvido por meio do desenho metodológico de um estudo de caso, que permitiu sistematizar por 12 meses a experiência de desenvolvimento de clubes juvenis que buscaram desenvolver valores, habilidades de vida e competência pré-laboral em 100 adolescentes e/ou jovens entre 12 e 21 anos, a partir de um estrato em situação de vulnerabilidade e risco diante do uso de drogas e de delinquência juvenil. Os resultados do trabalho de pesquisa revelaram que a implementação de programas preventivos que envolvem metodologias experientes, ativas e/ou participativas são uma estratégia pedagógica que mantém os adolescentes e/ou jovens motivados. Também foi evidenciado que o clube juvenil leva a prevenção do uso de drogas e delinquência juvenil a um nível que vai além da informação, gerando processos de metacognição e/ou reflexão que permitem o exercício de habilidades de vida. Como conclusão geral do trabalho, é possível afirmar que metodologias participativas que envolvem ação/reflexão como princípio pedagógico alcançam maior motivação nos jovens e garantem maior expectativa diante da mudança de comportamento.

\section{Palavras-chave}

Infância, juventude, uso de drogas, problemas sociais, infração. (fonte: Thesaurus Criminológico - Instituto Inter-regional de Pesquisa em Crime e Justiça das Nações Unidas - UNICRI). Prevenção ao crime. (fonte: autor). 


\section{Introducción}

Barrancabermeja es el segundo municipio distrital en importancia del departamento de Santander, con un total de 191.600 habitantes. Se encuentra ubicado en el corazón de Colombia, al occidente del departamento en la Provincia de Mares, margen oriental del río Magdalena; se extiende sobre este gran valle, irrigado por los ríos Sogamoso, La Colorada y Opón, con una latitud Norte de $7^{\circ} 03$ 48"; una longitud oeste de $73^{\circ} 5150^{\prime \prime}$ y con una altitud sobre el nivel del mar de 75,94 metros. El municipio se encuentra en la cuenca hidrográfica del Magdalena Medio. Cuenta con dos sistemas de ciénagas y gran variedad de caños y quebradas; como son entre otros las ciénagas San Silvestre, El Llanito, Zapatero, Juan Esteban y Opón, las quebradas El Llanito, Cremosa, Zarzal y Vizcaína y los caños El Llanito, San Silvestre y El Tigre. La extensión total de Barrancabermeja es de 1.347,83 km2; está compuesta por $30,37 \mathrm{~km} 2(2,24 \%)$ de zona urbana y I.317,46 km2 $(97,76 \%)$ de área rural, la temperatura oscila entre $20^{\circ} \mathrm{C}$ y $37^{\circ} \mathrm{C}$ con $28^{\circ} \mathrm{C}$ de tempera-

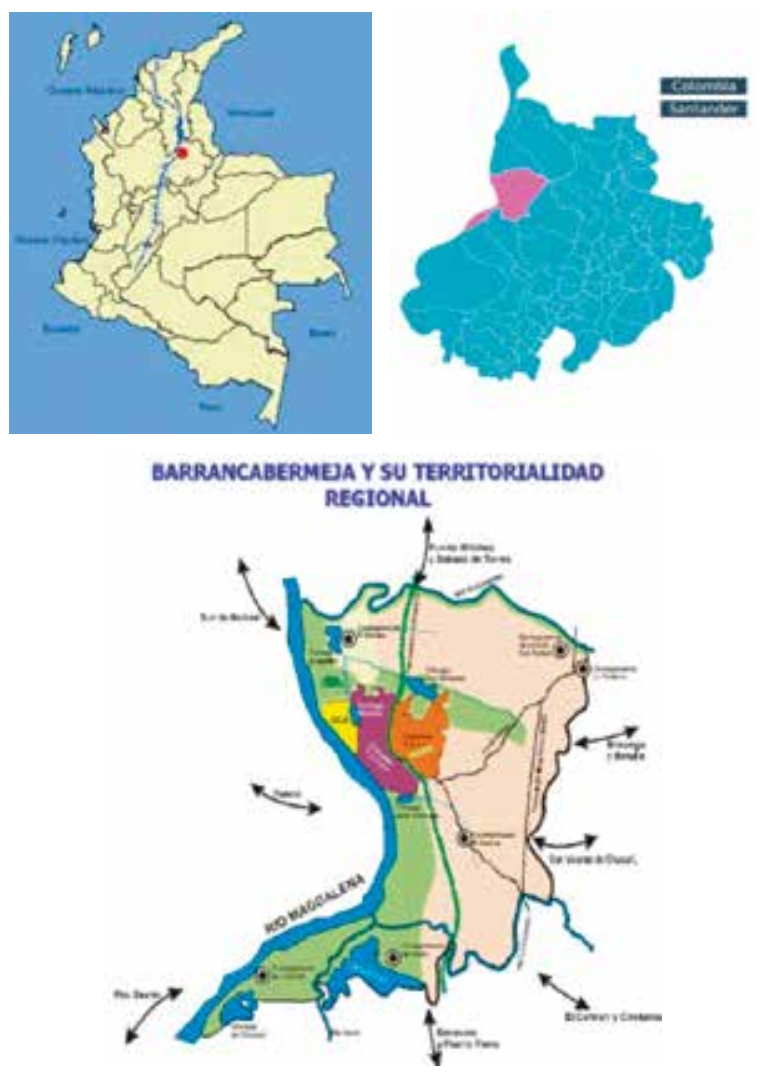

Figural. Municipio de Barrancabermeja

Fuente:http://blogjbarahona.blogspot.com/20I5/08/area-barrancabermeja-esunaciudad.html tura media. El municipio limita con los siguientes municipios: al norte con Puerto Wilches, Sabana de Torres y Girón, al sur con Puerto Parra, Simacota y San Vicente de Chucurí, al oriente con San Vicente de Chucurí y Betulia y al occidente con Yondó (Antioquia) (Chaparro, 20l5).

Barrancabermeja cuenta con una economía de enclave petrolera que tuvo sus inicios en el año 1916, con la explotación del pozo Cira Infantas (Otero, 20I5). En este municipio se encuentran las instalaciones de una de las refinerías más grandes de Colombia, Ecopetrol, creada el 25 de agosto de 195I.

Desde sus inicios de vida municipal Barrancabermeja se ha caracterizado por ser una región con diversas problemáticas socioculturales, ambientales y económicas, a raíz de varios factores, entre los cuales se destacan: (i). Su posición geográfica a orillas del río Magdalena, en la región media, lo que la ubica como un corredor estratégico de conectividad con todo el territorio nacional (por vía fluvial, terrestre, ferroviaria y aérea), situación que la ha hecho botín de disputa entre grupos armados ilegales (GRAI). (ii). Por su acelerado y desordenado crecimiento debido a las migraciones que generó el auge del oro negro, lo cual ha conllevado la proliferación de barrios subnormales, y junto a ello el crecimiento de los cordones de pobreza y surgimiento de hechos de inseguridad ciudadana (Molina, 2008).

Muchos de los problemas de inseguridad ciudadana que padece el creciente municipio de Barrancabermeja se relacionan con el fenómeno de cultivo, distribución y consumo de drogas. Fenómeno sociocultural que en los años setenta y ochenta se tomó el corredor del Magdalena Medio' y repercutió de manera directa en la dinámica de inseguridad que caracteriza a Barrancabermeja, quizá por ser esta ciudad el eje administrativo y comercial de la región. Una vez posicionada la problemática de cultivos ilícitos en el Magdalena Medio, Barrancabermeja sucumbió al flagelo de la distribución de drogas, hecho que en su momento fue favorecido y alimentado por condiciones propias del puerto petrolero, como eran la presencia de GRAI, las bandas criminales, cordones de pobreza, necesidades básicas insatisfechas, adolescentes y jóvenes sin proyecto de vida, sin posibilidad de estudio ni trabajo, entre otras ${ }^{2}$.

I Específicamente los municipios del sur de Bolívar, Canta Gallo, San Pablo, Simití y Santa Rosa con sus veredas y corregimientos. Entre los que se destaca Pozo Azul, Aguas Lindas, San Blas, El Paraíso, Monte Rey, Santa Lucía y San Joaquín.

2 Según estadísticas del Ministerio de Educación Nacional (2020) de un total de 18.172 jóvenes en edades entre los 17 y 21 años solo el $35,65 \%$ se encontraba en el sistema educativo. El resto, es decir II.693 (64,35\%) estaba por fuera del sistema educativo. 
Al respecto del problema de producción, distribución y consumo de drogas en Barrancabermeja, es posible ubicar algunas de las particularidades de este fenómeno en dicho contexto. Las mismas fueron descritas en dos estudios locales: I. El primero desarrollado por el Ministerio de Justicia y la Oficina de las Naciones Unidas Contra la Droga y el Delito (UNODC) (20 I5): Atlas de la caracterización regional de la problemática asociada a las drogas ilícitas en el departamento de Santander. El segundo, por la Fundación Reeducativa Profuturo (2014): "Prevalencia del consumo de drogas y factores de riesgo y protección en estudiantes de colegios de Barrancabermeja".

Según el trabajo del Ministerio de Justicia y UNODC (2015) el municipio de Barrancabermeja pasó de ser un corredor de tránsito de drogas en los años ochenta y noventa a ser una región productora y consumidora. En el estudio se indica que:

Hace algunos años, el consumo de SPA era percibido como un problema ajeno, no obstante, la llegada a la ciudad de un importante número de personas en busca de oportunidades de empleo y la necesidad de los grupos de narcotráfico de evitar las acciones de control, generaron un escenario propicio para el expendio al menudeo (Ministerio de Justicia \& UNODC, 2015, p. 153).

Según esta misma investigación las drogas que se distribuyen en la ciudad tienen diversas procedencias:

La marihuana llega de Bucaramanga, la base de coca delSur de Bolívary el clorhidrato de cocaína y la denominada marihuana variedad Crippi de Medellín. Pese a la magnitud del fenómeno, las autoridades municipales manifiestan que la incidencia del microtráfico es todavía baja en comparación con otras ciudades (Ministerio de Justicia \& UNODC, 2015, p. 154).

Los puntos más críticos de expendios y consumo de SPA son particularmente las comunas I y 7 . En la comuna I, los barrios;

El Dorado, Arenal y la Victoria, el Sector del Muelle, hay presencia de barreras invisibles asociadas al microtráfico, en esta zona se ubicaba la olla más grande del Municipio, que fue desmantelada de acuerdo a la directriz del gobierno nacional. Sin embargo, como consecuencia de esta intervención, el negocio se atomizó por toda la ciudad y hoy en día es más difícil establecer dónde se ubican los expendios y quiénes son los grupos que los manejan (Ministerio de Justicia y UNODC, 2015, p. 154).

Igualmente, en el trabajo de Ministerio de Justicia y UNODC (2015) se afirma que Barrancabermeja pasó de ser una zona de conflicto sociopolítico a tener como principal motivación de conflicto el control territorial y la disputa del negocio de drogas. Así mismo, se argumenta que el fenómeno del microtráfico se ha extendido a colegios y centros educativos. También el estudio señala que en Barrancabermeja hacen presencia bandas criminales, que no solo controlan el negocio del narcotráfico en el municipio, sino que también lo hacen a gran escala en el territorio del Magdalena Medio.

La segunda investigación, desarrollada por la Fundación Reeducativa Profuturo (2014) se centró en el consumo de drogas y los factores de riesgo que tienen los adolescentes o jóvenes de los colegios de Barrancabermeja: entre los resultados más importantes de este trabajo estuvieron: (i). El I4,I \% de adolescentes o jóvenes en edades entre los 12 y 18 años alguna vez en su vida consumió droga ilegal; siendo la marihuana la de mayor uso con un $7 \%$ de prevalencia en el último año. (ii). En lo que respecta al consumo de drogas legales como cigarrillo, alcohol y medicamentos, los datos revelaron que el $50 \%$ de los adolescentes o jóvenes del puerto petrolero alguna vez en su vida ingirió alcohol, el $20 \%$ alguna vez en su vida consumió cigarrillo y el $4 \%$ alguna vez empleó algún tipo de medicamento sin prescripción médica. (iii). En cuanto a factores de riesgo el estudio halló que más del $40 \%$ de los estudiantes entrevistados afirmó tener amigos consumidores de drogas legales o ilegales. Igualmente encontró que más del $80 \%$ de los estudiantes entrevistados aseveró que su papá o mamá consumen alcohol; con relación a las drogas ilegales los estudiantes en un $25 \%$ afirmaron que algún miembro de su familia es consumidor de droga ilegal. (iv). El trabajo reveló que la droga es de fácil adquisición en el contexto comunitario de los estudiantes.

Frente a este panorama de riesgo de consumo de drogas y delincuencia identificado en los adolescentes - jóvenes de los colegios de Barrancabermeja, el grupo de investigación de la Fundación Reeducativa Profuturo decidió dar un paso más en el trabajo de prevención de consumo de drogas, y llevó a cabo una investigación que permitió evidenciar o describir los efectos o impactos positivos de un programa psicoeducativo de intervención comunitaria (clubes 
juveniles), cuyo objetivo central fue el de prevenir el consumo de drogas y el surgimiento de conductas delictivas en población adolescente o joven.

Para el diseño teórico y metodológico del programa se tomaron experiencias previas como las que publica la Organización Panamericana de la Salud (OPS) (200l). En el plano de implementación de programas de habilidades para la vida como factor de protección en el área de la salud se examinó Mantilla (200I). En el campo del desarrollo de habilidades para la vida como componente transversal en el ámbito socioeducativo, se consultaron los investigadores Pérez (2012). En el área de la investigación de habilidades sociales para la prevención del consumo de drogas se consultó inicialmente a la Fundación Jacobs (20II) y posteriormente a Díaz y Mejía (20l8). En el ámbito de la implementación de clubes juveniles como una estrategia de formación juvenil, se tuvieron en cuenta los revisaron los lineamientos del Instituto Colombiano de Bienestar Familiar (ICBF) (20II) y el trabajo de Malagón (2017). Finalmente, en el tema del paradigma del aprendizaje experiencial o vivencial se asumieron los aportes de Gómez (20l I).

Partiendo de estos antecedentes conceptuales y metodológicos de investigación, y de la línea base de la problemática de producción, distribución y consumo fundamentada en los hallazgos de los diagnósticos ya citados, se diseñó e implementó el programa "Clubes juveniles, una estrategia de aprendizaje experiencial para la prevención del consumo de drogas y delincuencia juvenil" con cinco componentes que incorporan el enfoque de la prevención más allá de la información, como lo evidencia la Fundación Reeducativa Profuturo en sus diferentes prácticas y trabajos. Los adolescentes o jóvenes no cambian su comportamiento a partir de la información, sino que para que se dé un cambio o modificación de conducta se requiere desarrollar en ellos habilidades o capacidades para la vida.

\section{Método}

\section{Diseño}

La presente investigación se inscribe en los estudios de caso cualitativos de tipo descriptivo, y se propuso identificar y describir la efectividad de la estrategia educativa de los clubes juveniles como método de aprendizaje experiencial que favorece la prevención del consumo de drogas y la delincuencia juvenil.

En ese sentido, este diseño es apropiado para el presente estudio, en tanto que con él no se buscó entender o explicar el consumo de drogas ni la delincuencia en jóvenes; sino describir o ilustrar la eficiencia de un programa psicoeducativo de intervención comunitaria en la prevención del consumo de drogas y la delincuencia en población juvenil. Así mismo, buscó demostrar que el desarrollo de habilidades para la vida es un factor de protección que ayuda a atrasar, disminuir o desaparecer el consumo de drogas y la delincuencia juvenil (Stake, 1999).

Se tomó la opción de una investigación cualitativa descriptiva (Bonilla \& Rodríguez, 1997), con un diseño de caso instrumental porque se procuró entender en profundidad la efectividad del programa psicoeducativo en la prevención comunitaria del consumo de drogas y la delincuencia juvenil; lo cual no es posible desde métodos cuantitativos de investigación, porque estos no se centran en las experiencias vividas, aspecto que busca esta investigación. El estudio de caso permitió obtener los datos de investigación desde una variedad de fuentes cualitativas que recogen las vivencias como: entrevistas, talleres, registros de campo, observación directa, observación de los participantes, entre otros (Taylor, 1992).

\section{Población}

Adolescentes o jóvenes de los barrios San Luis y Buenos Aires II, comuna uno del municipio de Barrancabermeja. Según censo de la Fundación Reeducativa Profuturo los dos asentamientos humanos estaban constituidos por un total de 350 hogares (200 en el barrio Buenos Aires II y I50 en el barrio San Luis). Estos sectores fueron el producto de procesos de invasión de lotes baldíos en zonas de riesgo natural o ambiental, y no cuentan con todos los servicios públicos básicos. Actualmente son barrios de estrato socioeconómico uno (es decir, barrios subnormales cuyos habitantes tienen ingresos socioeconómicos muy bajos).

En el censo socioeconómico también se pudo identificar que en los dos barrios vivían un total de 250 adolescentes o jóvenes en rango de edades entre los 12 y $2 \mathrm{I}$ años. Como principales problemáticas de los jóvenes se detectó la pobreza, la exclusión social, la desescolaridad, el desempleo, la desocupación y la no consolidación de un proyecto de vida. Igualmente se identificó que la ubicación geográfica del barrio se constituye en un factor de alto riesgo frente al consumo de drogas y de delincuencia juvenil (por lo aislado del sector, es un lugar frecuentado por otros jóvenes consumidores de drogas residentes de otros sectores o barrios del municipio). 
Figura 2. Barrios San Luis y Buenos Aires II
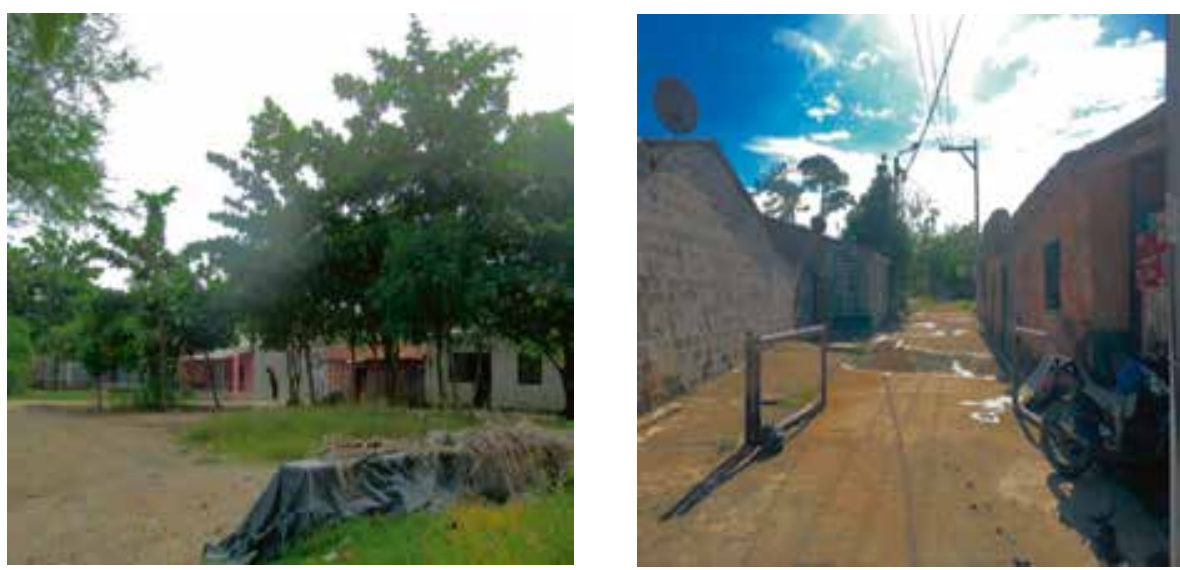

Fuente: Fundación Reeducativa Profuturo, fotos que forman parte del archivo fotográfico del proyecto.

\section{Muestra}

Se seleccionó una muestra por conveniencia, es decir no probabilística, en tanto que la investigación se ejecutó desde el enfoque metodológico del estudio de caso de corte cualitativo. Para la conformación de la muestra se tuvieron en cuenta los siguientes criterios de conveniencia: estar en edades entre los 12 y 21 años, querer participar voluntariamente en el programa, tener el permiso o consentimiento firmado por parte de sus padres si son menores de edad o por ellos en caso de ser mayores de edad, y ser residentes de los barrios San Luis y Buenos Aires II de la comuna uno del municipio de Barrancabermeja.

Al final se consolidó una muestra de 100 adolescentes o jóvenes de los cuales 44 fueron mujeres y 56 hombres (como se muestra en la Tabla I). Los mismos se organizaron en 5 clubes juveniles, cada club con 20 integrantes. La razón por la que se seleccionó este rango de edad para hacer la investigación está relacionada con los estudios internacionales, nacionales y regionales; los cuales señalan que la población que presenta mayor rango de consumo o mayor riesgo de consumo está en edades entre los 12 y 21 años de edad (Ministerio de Justicia y Protección Social, 2015; ONU, 2015; Fundación Reeducativa Profuturo, 2014).

\section{Instrumentos de recolección de información}

Diario de campo. Se utilizó como un instrumento de recolección de información del trabajo de formación semanal desarrollado con los adolescentes o jóvenes; el mismo permitió registrar y sistematizar la observación de diferentes aspectos durante la puesta en marcha del programa.

Talleres experienciales. Se efectuaron 36 talleres experienciales o vivenciales de tres horas cada uno, uno cada ocho días. Los mismos fueron diseñados por el personal involucrado en la investigación. Se trabajaron actividades prácticas en torno a temas centrales relacionados con factores de riesgo frente al consumo de drogas, las 10 habilidades para la vida, los valores absolutos y las competencias prelaborales. Todos diseñados previamente pensando en actividades que exigieran la aplicación de los cuatro momentos del aprendizaje experiencial.

Tabla I.

\section{Características de la muestra del estudio}

\begin{tabular}{|c|c|c|c|c|c|c|c|}
\hline \multirow[b]{2}{*}{$\begin{array}{c}\text { Rango de } \\
\text { edad }\end{array}$} & \multicolumn{2}{|c|}{ Género } & \multicolumn{4}{|c|}{ Escolaridad } & \multirow{2}{*}{$\begin{array}{l}\text { Número de } \\
\text { jóvenes } \\
\text { seleccionados }\end{array}$} \\
\hline & Femenino & Masculino & Primaria & Bachillerato & Técnica & $\begin{array}{l}\text { Por fuera } \\
\text { del sistema } \\
\text { escolar }\end{array}$ & \\
\hline $12-14$ & 16 & 24 & 5 & 35 & 0 & 0 & 40 \\
\hline $15-18$ & 22 & 18 & 0 & 35 & 3 & 2 & 40 \\
\hline$|9-2|$ & 6 & 14 & 0 & 7 & 5 & 8 & 20 \\
\hline Total & 44 & 56 & 5 & 77 & 8 & 10 & 100 \\
\hline
\end{tabular}

Fuente: elaboración propia. 
Un primer momento de la actividad tuvo que ver con la exposición a la experiencia concreta, un segundo momento exigió la observación o la reflexión sobre la experiencia (metacognición), un tercer momento planteó la conceptualización o abstracción sobre la experiencia (aprendizaje) y un último momento correspondió a la experimentación activa (acción) o aplicación de lo aprendido en los diferentes contextos.

Registros fotográficos. Se tomaron fotos e imágenes de todas las actividades a fin de tener evidencia de las mismas. Las fotos permitieron reconstruir y analizar posteriormente lo realizado en las sesiones de trabajo. Para este proceso se solicitó el consentimiento informado de padres de familia.

Entrevista semiestructurada. Se utilizó como un medio de comunicación interpersonal establecida entre los participantes de los clubes juveniles, sus padres y los investigadores, con el fin de obtener respuestas verbales a los interrogantes hechos sobre el problema propuesto. Las entrevistas permitieron conocer la realidad cultural y socioeconómica de las familias e identificar los factores de riesgo frente al consumo de drogas y la delincuencia juvenil.

Observación participante. Esta técnica de recolección de información facilitó interactuar con los participantes en el programa y observar los comportamientos e interacciones sociales de los mismos. Igualmente permitió evidenciar el progreso de los participantes en lo que respecta al desarrollo de valores, habilidades para la vida y competencias prelaborales como estrategia de prevención.

\section{Procedimiento}

La investigación forma parte del proyecto investigativo institucional titulado "Clubes juveniles, una estrategia de aprendizaje experiencial para la prevención del consumo de drogas y delincuencia juvenil”. Proyecto financiado por la Fundación Bolívar-Davivienda y la Fundación Reeducativa Profuturo, esta última a través de su grupo de investigación Centro Regional de Investigaciones Humanas, Sociales y Ambientales Profuturo.

La primera organización aportó $\$ 25.000 .000$ con los que se cubrieron los gastos de materiales pedagógicos y logísticos para el desarrollo de la propuesta educativa (clubes juveniles); y la segunda organización aportó $\$ 32.000 .000$ para cubrir los gastos del personal o talento humano con el que se ejecutó el trabajo pedagógico e investigativo.

El grupo humano con el que se desarrolló la investigación estuvo constituido por: un director de proyecto (especialista en temas de niñez y juventud y consumo de drogas), tres psicopedagogos (expertos en trabajo educativo con jóvenes), una psicóloga (experta en temas de habilidades para la vida y desarrollo de competencias prelaborales), cuatro líderes jóvenes del sector donde se desarrolló el trabajo que fueron los promotores o facilitadores del trabajo en la comunidad. Igualmente, el grupo humano estuvo conformado por seis estudiantes de último semestre de psicología que actuaron como voluntarios en el desarrollo del trabajo investigativo.

La finalidad del proyecto fue desarrollar valores, habilidades para la vida y competencias prelaborales en los adolescentes o jóvenes que participaron en el proyecto, como se ilustra en la Tabla 2.

El proyecto se desarrolló en ocho meses y en cinco momentos o etapas, como se muestra en la Tabla 3.

Figura 3. Equipo humano o profesional
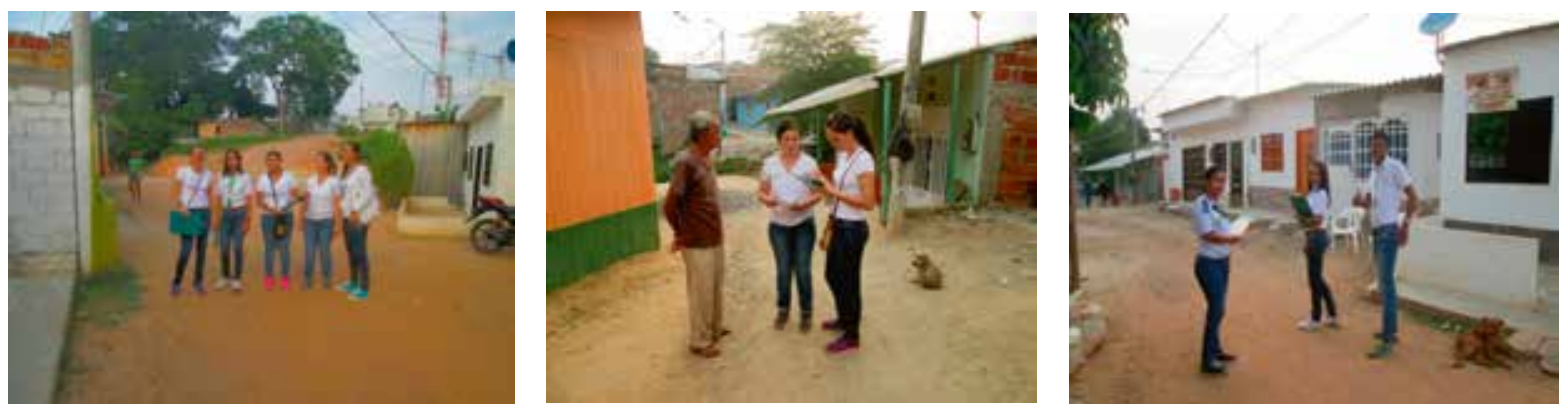

Fuente: Fundación Reeducativa Profuturo, fotos que forman parte de los archivos del proyecto. 
Tabla 2.

\section{Finalidad de los clubes juveniles}

\begin{tabular}{|c|c|c|}
\hline \multicolumn{3}{|c|}{$\begin{array}{l}\text { Finalidad del proyecto: } \\
\text { Los clubes juveniles tuvieron como propósito central desarrollar valores, habilidades } \\
\text { para la vida y competencias prelaborales }\end{array}$} \\
\hline Valores & Habilidades para la vida & $\begin{array}{c}\text { Competencias } \\
\text { prelaborales }\end{array}$ \\
\hline Verdad & Autoconocimiento & Tener iniciativa \\
\hline Rectitud & Empatía & Saber planear y resolver problemas \\
\hline $\mathrm{Paz}$ & Comunicación asertiva & Saber escuchar \\
\hline Amor & Relaciones interpersonales & Seguimiento de instrucciones y órdenes \\
\hline \multirow[t]{6}{*}{ No violencia } & Toma de decisiones & Tener disciplina o responsabilidad \\
\hline & Manejo de problemas y conflictos & Saber trabajar en equipo \\
\hline & Pensamiento creativo & Tener apertura al cambio \\
\hline & Pensamiento crítico & $\begin{array}{c}\text { Tener plasticidad mental y } \\
\text { adaptación a nuevas situaciones }\end{array}$ \\
\hline & Manejo de emociones y sentimientos & \\
\hline & Manejo de tensión - estrés & \\
\hline
\end{tabular}

Fuente: elaboración propia.

Tabla 3.

\section{Etapas del proyecto}

\begin{tabular}{|c|c|c|c|c|c|}
\hline Etapas & Actividades \\
\hline $\begin{array}{c}\text { I. Línea base de factores de riesgo de } \\
\text { los jóvenes de la comunidad }\end{array}$ & $\begin{array}{c}\text { Se identificaron los factores de riesgo de los jóvenes frente al } \\
\text { consumo de drogas y delincuencia juvenil. Para ello se aplicó } \\
\text { una encuesta semiestructurada que permitió establecer una } \\
\text { línea base con relación al consumo y factores de riesgo }\end{array}$ \\
\hline
\end{tabular}

\section{Convocatoria}

III. Formación

IV. Réplica

V. Construcción de sentido de vida
Se convocó a la participación en el programa, se hicieron las inscripciones y se firmaron los consentimientos informados; se aplicó una entrevista semiestructurada tipo encuesta que permitió hacer una caracterización socioeconómica

\begin{tabular}{|c|c|}
\hline III. Formación & $\begin{array}{l}\text { Talleres y experiencias vivenciales. Estos talleres vivenciales fueron } \\
\text { diseñados por el equipo profesional involucrado en el proyecto }\end{array}$ \\
\hline IV. Réplica & $\begin{array}{l}\text { La réplica consistió en que los adolescentes o jóvenes aplicaran lo } \\
\text { aprendido en su barrio y la construcción de proyecto de vida o } \\
\text { sentido de vida como un compromiso personal de crecimiento con } \\
\text { la propia existencia. Las } 12 \text { actividades de réplicas se enfocaron en } \\
\text { poner en práctica los } 5 \text { valores, las } 10 \text { competencias para la vida y } \\
\text { las } 8 \text { las competencias prelaborales. Como se ilustra en la Figura } 2\end{array}$ \\
\hline V. Construcción de sentido de vida & $\begin{array}{l}\text { Etapa transversal al proyecto. Durante todo el proceso de formación } \\
\text { los adolescentes o jóvenes en compañía de la psicóloga y formadores } \\
\text { iban construyendo o redefiniendo su proyecto o sentido de vida }\end{array}$ \\
\hline
\end{tabular}

Fuente: elaboración propia. 


\section{Aspectos éticos}

Teniendo en cuenta el hecho de que el $70 \%$ de los potenciales participantes en el programa fueron menores de edad, el abordaje de los mismos se hizo a través de sus padres o tutores, a quienes se les presentó o explicó los objetivos, los requisitos y los alcances del programa, sumado a esto se les pidió autorización o permiso firmado para que el menor pudiera participar en el programa (véase apéndice). Para proteger la integridad de los menores y velar por el normal funcionamiento del programa se conformó un grupo de padres de familia que acompañó e hizo veeduría en el desarrollo de las actividades del programa. Este comité se reunía cada quince días con los profesionales de la Fundación para revisar y hacer sugerencias y retroalimentación del trabajo, igualmente las reuniones se podían hacer con más frecuencia según las necesidades o urgencia que se presentara.

En cuanto al tratamiento de los datos: la información se recogió manteniendo el principio de respeto a la privacidad de los adolescentes, jóvenes y sus familias que voluntariamente participaron en el estudio. Los datos se transcribieron utilizando códigos de identificación y tabulados por investigadores, lo que permitió mantener una cadena de custodia sobre los mismos. En ninguna circunstancia se reveló la identidad de los participantes en el estudio.

\section{Resultados}

Los resultados se organizaron en cuatro partes según los objetivos del estudio. Cada una de ellas da cuenta de la revisión teórica que se ejecutó: construcción metodológica; trabajo de campo y recolección de información; organización y análisis de resultados.

\section{Revisión de antecedentes teóricos y metodológicos para el diseño del programa psicoeducativo}

En lo que respecta a la categoría conceptual de habilidades para la vida aplicada al área de la salud se revisaron los aportes propuestos por la OPS (200I). Específicamente su propuesta metodológica en torno a la implementación de habilidades para la vida, la OPS incorpora como un eje transversal de todas sus intervenciones en salud, con población adolescente - jóvenes, el desarrollo de habilidades para la vida como una estrategia central para prevenir diversas situaciones de riesgo en salud con esta población. La OPS define las habilidades para la vida como

[...] competencias personales e interpersonales que favorecen el desempeño de los adolescentes y/o jóvenes en diferentes contextos como el familiar, el social, el escolar y laboral, entre otros. Destrezas de carácter afectivo, cognitivo, emocional, comunicativo y comportamental que ayudan a tener una mayor adaptabilidad y mejor desempeño en la vida (p. 3).

Según las investigaciones y trabajos aplicados de la OPS las habilidades para la vida son un componente esencial para el desarrollo saludable de niños, niñas, adolescentes y jóvenes.

Un segundo referente que se revisó para el diseño del programa estuvo relacionado con el tema de habilidades para la vida en el contexto socioeducativo, en ese sentido, se indagó por el modelo de la Fundación Fe y Alegría. Organización sin ánimo de lucro que hace varias décadas enseña a vivir y a convivir a niños y niñas en ambientes de barrios pobres. Según Fe y Alegría las habilidades para la vida son una manera efectiva de educar desde una perspectiva participativa y creativa, tanto a mujeres como a hombres durante todo el ciclo vital; es decir, desde la niñez pasando por la adolescencia y la juventud hasta la adultez. Para la Fundación Fe y Alegría las habilidades para la vida se asocian estrechamente con el concepto de competencia psicosocial: "la habilidad de una persona para enfrentarse exitosamente a las exigencias y desafíos de la vida diaria" (Mantilla, 200I, p. 7).

Desde esta línea teórica, se resaltó lo relacionado con el enfoque psicosocial como base para la construcción del programa de habilidades para la vida que se implementó con los adolescentes o jóvenes del municipio de Barrancabermeja. En tanto que las competencias psicosociales son básicas para afrontar problemas de salud ligados con el comportamiento y el mundo afectivo.

Un tercer trabajo consultado como antecedente en el diseño del programa de intervención fue el de Pérez (20I2), pues aporta a la claridad conceptual de la categoría habilidades para la vida como estrategia educativa para la prevención del consumo de drogas. En este trabajo la investigadora planteó que existe una amplia evidencia científica sobre el éxito de los programas escolarizados con un enfoque de habilidades cuyo objetivo ha sido la prevención de consumo de drogas en niños y adolescentes. En ese sentido, se describen las características de varios 
programas encaminados a desarrollar habilidades para la vida, entre los cuales se destacan: (i). Programa de Entrenamiento en Habilidades para la Vida (Life Skills Training Program, LST). El LST (NIDA, 2004) fue un programa universal para estudiantes que les enseñaba habilidades sociales, cognitivas y emocionales, además de proporcionar conocimientos sobre drogas y desmitificar creencias erróneas asociadas a estas. (ii). Programa Chimalli, modelo de prevención basado en los riesgos psicosociales. Su objetivo principal fue hacer educación preventiva y crear una protección en los individuos y en las comunidades (Castro et al., 1999). (iii). Programa "Construye tu Vida sin Adicciones" (López, 2003). Tuvo como principal objetivo la conformación de estilos de vida que permitían desplegar al máximo el potencial de cada persona y propiciar con ello condiciones que mejoren la calidad de vida de las familias y comunidades. (iv). Programa "Yo quiero yo puedo" (Pick \& Givaudan, 2010), cuyo objetivo era desarrollar en niños las habilidades que les permitan manejar adecuadamente las situaciones de riesgo y fortalecer factores protectores como la comunicación y la unidad familiar, para prevenir las conductas antisociales como el abuso de drogas.

Un cuarto antecedente teórico fue la investigación de Díaz y Mejía (20I8). Estas investigadoras ubicaron como primer referente teórico a la Unicef (2017), quien define las habilidades para la vida "como recursos psicosociales e interpersonales que ayudan a la gente a tomar decisiones con conocimiento de causa, comunicarse de forma efectiva y desarrollar unos recursos para manejar y auto gestionar una vida saludable y productiva" (p. 4). Otra referente que citan las autoras es la Fundación Jacobs (20l I), quien plantea que "las habilidades para la vida pueden aplicarse a acciones dirigidas hacia uno mismo, hacia otras personas, o hacia el entorno local. Su objetivo consiste en favorecer la salud y el bienestar en todos estos niveles" (p. 10).

Para Díaz y Mejía (2018) desde esta visión, el enfoque de habilidades para la vida que se propone en los procesos de educación formal se centra en la perspectiva de salubridad y recoge los intereses del sistema capitalista en torno a una humanidad productiva. Los resultados de esta investigación mostraron que si bien han existido esfuerzos institucionales para promover el desarrollo de habilidades para la vida desde el enfoque que se ha descrito, no son suficientes para que los adolescentes, efectivamente, las desplieguen; por ende, si la pretensión es prevenir conductas de riesgo como la delincuencia y el consumo de drogas es posible que no se alcance el objetivo de manera satisfactoria.
Un quinto documento examinado que dio soporte metodológico al programa de clubes juveniles fue la propuesta o trabajo técnico del ICBF (20II). Según el ICBF los clubes juveniles son

[...] escenarios con enfoque diferencial de encuentro, participación y formación para la inclusión social de niños, niñas y adolescentes donde se promueve el desarrollo de competencias para la vida que permiten afrontar eficazmente los retos cotidianos por medio del ejercicio de la ciudadanía y la democracia (p. 2).

Por su parte, Malagón (2017) plantea que los clubes son un instrumento con recorrido histórico que ha demostrado su utilidad para potenciar la integración social y el talento de los y las jóvenes. Malagón profundiza en el concepto de club juvenil, al respecto advierte que como su nombre indica, un club juvenil es una agrupación compuesta por personas jóvenes, normalmente menores de 18 años, aunque los límites de edad pueden ser variables según los casos. El rasgo principal de los mismos es el que los jóvenes participan activamente en su organización y actividades, es decir las lideran. Los clubes juveniles son formas de afiliación juvenil que admiten distintos idearios, estilos y modalidades de funcionamiento. Suelen ser alternativas de ocio y tiempo libre en horarios extraescolares, fines de semana y periodos vacacionales, aunque igualmente pueden existir, funcionar y estar integrados en el proyecto de los centros educativos.

En cuanto a la categoría de aprendizaje experiencial o vivencial, se tiene que fue fundamental para entender y elaborar la propuesta psicoeducativa de intervención, para ello se retomó un séptimo trabajo, el del psicólogo Gómez (20II). El autor recogió los aportes de Kolb et al. (200I), quienes identifican la importancia del papel que desempeña la experiencia en el proceso de aprendizaje. El aprendizaje es el proceso por medio del cual construimos conocimiento mediante un proceso de reflexión y de "dar sentido" a las experiencias. Siguiendo esta línea, los trabajos de Gómez (20II) se centran en explorar los procesos cognitivos asociados al abordaje y procesamiento de las experiencias, y en identificar y describir los diferentes modos en que se realizan dichos procesos, esto es, los distintos estilos individuales de aprendizaje. Sus investigaciones se basan en desarrollos y trabajos teóricos previos de autores como Jean Piaget, John Dewey y Kurt Lewin. 


\section{Definición de los elementos metodológicos del programa psicoeducativo}

A continuación, se describen los lineamientos de la propuesta metodológica de formación vivencial denominada "Clubes juveniles, una estrategia de aprendizaje experiencial para la prevención del consumo de drogas y delincuencia juvenil”. Estrategia que se construyó y aplicó en el presente estudio de caso para observar la efectividad de la misma en la prevención del consumo de drogas y la delincuencia juvenil en adolescentes o jóvenes en condición de riesgo y vulnerabilidad.

Fundamentación. La idea sobre la cual se fundamentó el diseño del programa se apoyó en la evidencia que arrojaron los resultados de la investigación de la Fundación Reeducativa Profuturo (20/4). De acuerdo con la respuesta obtenida en las preguntas que indagaron por el conocimiento que tenían los estudiantes sobre la problemática del consumo droga y la calidad de los programas que se desarrollaban en los contextos escolares. El $80 \%$ de los entrevistados contestó que tenía suficiente información sobre el problema de consumo de drogas y que la calidad de los programas de prevención en los colegios era buena. A la pregunta por si los programas han contribuido a cambiar su comportamiento frente al consumo de drogas un $75 \%$ respondió que no. Lo que llevó a la Fundación Reeducativa Profuturo a contemplar la hipótesis de que los jóvenes no cambian los comportamientos a partir de la información que reciben, la cual es necesaria pero no suficiente para lograr un verdadero y duradero cambio. El mismo requiere que se dé un modelamiento a través de la experiencia y del desarrollo de habilidades o capacidades para la vida. A partir de esta hipótesis se ejecutó este programa que tuvo como fin comprobar dicha conjetura.

Para lograrlo, el programa incorporó cuatro pilares transversales en la formación, dos teóricos y dos metodológicos. Los pilares teóricos se relacionan con las teorías sobre consumo de drogas y delincuencia juvenil y con el desarrollo de habilidades para la vida. Los pilares metodológicos estuvieron relacionados con los clubes juveniles como estrategia de formación y el aprendizaje experiencial como vía expedita para enseñar manteniendo vivas las expectativas y motivación en los jóvenes.

Población beneficiaria. El programa está diseñado para adolescentes o jóvenes en edades entre los 18 y 2 I años, de estrato I y 2 , en condición de riesgo frente al consumo de drogas y la delincuencia juvenil.

Estrategia de intervención comunitaria. Clubes juveniles, los cuales serán un espacio de encuentro y reconocimiento entre los adolescentes y jóvenes, en edades entre los 12 y 21 años. Cada club está pensado para ser constituido por un promedio entre 15 y 20 integrantes. A través de la enseñanza experiencial o vivencial se busca incentivar la práctica de valores provida, desarrollar habilidades para la vida y orientar en preferencias vocacionales $u$ ocupacionales, desplegando hábitos prelaborales. El propósito es que los adolescentes o jóvenes en condición de riesgo completen el ciclo de formación experiencial, a fin de que puedan construir un proyecto de vida que los proteja o aleje del consumo de drogas y la delincuencia juvenil. Los clubes juveniles se constituyen en espacios de socialización que les permitirá a los adolescentes - jóvenes reunirse cada ocho días para abordar de manera experiencial o práctica temas asociados con factores de riesgo y problemáticas ligadas al consumo de drogas y delincuencia juvenil, y los valores absolutos. Los mismos son liderados por los jóvenes en edades entre los 18 y 21 años, que a su vez estarán guiados $\mathrm{u}$ orientados por adultos capacitados para dinamizar o monitorear el proceso.

La idea es que cada club tenga su estructura administrativa, elabore un estatuto de funcionamiento, establezca roles y funciones al interior del club y construya conjuntamente un plan de acción por un año en torno al propósito de prevenir el consumo de drogas y la violencia juvenil entre los jóvenes del barrio. Finalmente, los clubes deben asumir una metodología de trabajo.

Los encuentros de cada ocho días tendrán como objetivo rendir cuentas o revisar el trabajo psicoeducativo-comunitario desarrollado por los integrantes del club durante la semana en el barrio. Asimismo, la reunión semanal de los clubes juveniles tendrá como propósito llevar a cabo actividades lúdico-recreativa, dinámicas grupales de integración y fortalecimiento del arraigo y sentido de pertenencia de los integrantes del club; por último, en las reuniones semanales se organizarán competencias al aire libre, establecidas de tal manera que permitan el aprendizaje experiencial o vivencial de las habilidades para la vida mediante la competencia grupal.

Estrategias experienciales de formación en habilidades para la vida. El aprendizaje experiencial tendrá dos momentos:

Primer momento: encuentros semanales de los clubes (sábados): los clubes establecerán un día y horario de reunión semanal, en los que trabajarán tres horas 
acompañados por un educador o psicólogo de la Fundación Reeducativa Profuturo, el trabajo en estos encuentros se dividirá en dos tiempos: a) dedicado a la evisión de lo que se ha hecho en el barrio durante la semana según el plan de acción del club, b) dedicado a aprender nuevos valores, habilidades para la vida, liderazgo social y competencias prelaborales (a través de actividades lúdicas y recreativas).

El club juvenil aplicará estrategias o metodologías lúdicas recreativas de aprendizaje experiencial como:

Cine-arte: se presentará una película apropiada para jóvenes, con una temática con la que se buscará identificar y analizar la importancia de algún valor específico o habilidad para la vida; los jóvenes verán el filme y al final se hará la reflexión mediada por el educador o psicólogo a cargo del grupo. Con esta actividad se buscará desarrollar habilidades para la vida como: el pensamiento crítico, el manejo de problemas y conflictos y la toma de decisiones. Además, se buscará interiorizar valores como el amor, la verdad, la honestidad, la paz, la responsabilidad, el respeto a la vida y la solidaridad.

Arte terapia: (utilizando técnicas como teatro, escultura y pintura) se les presentará a los jóvenes un tema y luego se le solicitará al grupo que elabore una muestra artística con lo planteado (obra de teatro, pintura o escultura), para esta actividad los estudiantes contarán con el apoyo de maestros de arte $\bigcirc$ artística. Esta actividad profundizará en el autoconocimiento y autoaceptación, en la expresión adecuada de sentimiento y manejo de emociones, relaciones interpersonales y pensamiento creativo; igualmente desarrollará valores como la tolerancia y el respeto por la diferencia.

Danza-terapia: se utilizará la danza como pretexto para enseñar de manera lúdica y vivencial valores y habilidades para la vida como: la cohesión, identidad grupal, trabajo en equipo, coordinación, seguimiento de órdenes, disciplina, expresión adecuada y asertiva de sentimientos y empatía; cada club en el transcurso del proyecto construirá una coreografía que lo represente como club, la cual será socializada en el evento clausura del proyecto.

Juegos al aire libre de competencia grupal: cada semana se elaborarán juegos al aire libre que posibiliten el despliegue de habilidades para la vida como: comunicación asertiva, resolución de problemas, toma de decisiones, manejo de tensión y estrés. Además, se estimularán competencias prelaborales como tener iniciativa, saber resolver problemas, tener plasticidad y adaptación a nuevas situaciones, seguir instrucciones, saber escuchar, saber planear, saber evaluar y responsabilidad.
Testimonios de vida o relatos de vida: con esta estrategia se pretende que los jóvenes aprendan valores, habilidades para la vida y competencias prelaborales a través de la experiencia y vivencias de otras personas líderes o exitosas en su contexto familiar, laboral y social. La idea con esta actividad es que los jóvenes fortalezcan la empatía, aprendan a tener comunicación asertiva, promuevan buenas relaciones interpersonales y valoren las oportunidades de la vida.

Segundo momento: retos o desafios mensuales. Una vez al mes los clubes juveniles se enfrentarán en un reto o desafío grupal que denominamos vivencia experiencial. (En la que cada club compite con los otros clubes). La intención de esta actividad de cierre mensual es evaluar lo aprendido por cada joven al interior de su club. Esta actividad se desarrollará en campo abierto en un lugar adecuado para enfrentar los retos previamente elaborados y pensados para reforzar lo aprendido, es decir los valores, habilidades para la vida y competencias prelaborales. Esta experiencia tiene como propósito el aprendizaje grupal o cooperativo, el objetivo es que los jóvenes aprendan a partir de las experiencias exitosas de los otros clubes y de los propios errores cometidos a la hora de enfrentar un reto.

La actividad tendrá tres etapas a acompañadas por el docente o psicólogo a cargo del grupo:

a. Conocimiento del desafío: el club se prepara y planea cómo enfrentar de manera adecuada y exitosa el reto.

b. Desarrollo del desafío: el club enfrenta el desafío y cada miembro del grupo asume un rol y una responsabilidad frente al mismo.

c. Evaluación de lo aprendido: se reflexiona sobre los valores, habilidades y competencias prelaborales que se requerían para resolver el reto, igualmente se analiza en qué se falló y cómo mejorar.

Réplica de lo aprendido y desarrollo de capacidades de liderazgo y responsabilidad social. Los jóvenes de los clubes participarán en actividades comunitarias (incluidas en el plan de acción del club) encaminadas a resolver situaciones de riesgo o situaciones problemas, identificadas por los mismos jóvenes y que afectan el desarrollo humano y social de su comunidad; con estas actividades los jóvenes se empoderan y ponen en práctica lo aprendido en los clubes juveniles. La idea es que aprendan a ser 
líderes en la acción o con la vivencia directa de gestionar procesos comunitarios. En total dentro del plan de trabajo se incorporaron doce actividades de réplica de lo aprendido en el club juvenil. Construcción de sentido y proyecto de vida. Este componente es transversal a la formación de los jóvenes y se desarrollará a lo largo de la ejecución del proyecto; este componente será guiado por los educadores y psicólogos que acompañan el proceso, el fin es que junto a la labor grupal se implemente un trabajo de seguimiento y crecimiento personal de cada uno de los jóvenes participantes en el proyecto, para ello se brindarán asesorías individuales y familiares, en las que hablará sobre el sentido y proyecto de vida. Se busca que al terminar el proyecto se pueda seguir en una segunda fase relacionada con la formación ocupacional, laboral y liderazgo social, y terminar posteriormente en un tercer momento que pueda plantear un proyecto de reinserción laboral a través de la empleabilidad o generación de proyectos productivos por parte de los jóvenes del sector.

\section{Resultados o hallazgos más significativos del estudio de caso}

Uno de los primeros hallazgos o resultados más importantes de la presente investigación está relacionado con la identificación de factores de riesgo que tienen los adolescentes o jóvenes en los barrios donde se desarrolló el proyecto frente al consumo de drogas o delincuencia juvenil. Estos resultados se obtuvieron a través de las entrevistas semiestructuradas hechas a los padres de familia o jóvenes que participaron en el proyecto. En las mismas se indagó por once aspectos que se asocian con características socioculturales, económicas y contextuales donde viven los jóvenes y su nexo con el consumo de drogas y delincuencia juvenil. Se encontraron los siguientes resultados:

Número de personas que viven en el hogar. En cuanto al número de personas que viven en cada uno de los hogares visitados en el barrio San Luis y Buenos Aires II se puede identificar que 80 de los 100 hogares visitados se encontraban en condición de hacinamiento, específicamente con un número superior de seis personas habitando en cada vivienda. Dato alarmante, pues denota las condiciones precarias de vida de los hogares visitados. Por otra parte, es de destacar que el resto de hogares (20) están conformados por un número de cuatro a tres personas habitando cada vivienda. De los anteriores resultados se puede concluir que el número de personas que habitan en las viviendas del barrio San Luis y Buenos Aires II es considerablemente alto.

Estrato socioeconómico. Los hallazgos revelaron que el estrato socioeconómico de los adolescentes o jóvenes que participaron en el programa era bajo. Del total de los hogares visitados el $95 \%$ se identificó como estrato uno y el $5 \%$ restante como estrato dos, lo cual va directamente conectado con condiciones de vida difíciles y condiciones de vulnerabilidad debido a los bajos ingresos económicos y problemas de sanidad.

Tipo de vivienda. A la pregunta de si la vivienda era arrendada o propia se encontró que el $85 \%$ de los hogares cuenta con vivienda propia y tan solo el $15 \%$ vive en arrendamiento.

Características de la jefatura del hogar. Se puede evidenciar que la jefatura económica o responsabilidad de los gastos del hogar recae en su mayoría sobre el padre, con un $50 \%$ de jefatura económica, y la madre con el $35 \%$. En cuanto a la jefatura de poder o de imposición de reglas recae en un $90 \%$ sobre la madre, quien asume el papel de jefe del hogar. Por otra parte, se destaca que esta función de llevar las riendas del hogar, los entrevistados no la consideran como responsabilidad compartida entre ambos miembros (padre y madre). Tan solo en una familia se encontró que un adulto mayor era jefe de hogar.

Afiliación o cobertura del sistema de salud. Se destaca que el $90 \%$ de los entrevistados señaló que los adolescentes o jóvenes que conforman el hogar cuentan con servicios médicos y tan solo un $10 \%$ correspondiente a dos entrevistados del estudio indicó que los jóvenes de su hogar no contaban con los servicios de salud, lo cual lleva a deducir que el estado de salud, bienestar y calidad de vida de los jóvenes en los hogares es una prioridad.

Ocupación de los adolescentes o jóvenes. El $80 \%$ de los entrevistados consideró que los adolescentes - jóvenes del hogar tienen ocupaciones o cargas académicas y tan solo el $20 \%$ reconoce estar en estado de desempleo o sin ocupaciones, entre un mes y dos años.

Actividades de tiempo libre. Se pudo apreciar que la principal ocupación de los adolescentes o jóvenes en sus tiempos libres era el deporte, específicamente el fútbol, representado en un $50 \%$; por otro lado, ver televisión es también significativo ( $25 \%$ ) en los jóvenes para ocupar parte de su tiempo libre. Tan solo el $5 \%$ de los entrevistados reconoció que los jóvenes no realizan actividades recreativas y el $20 \%$ indica que los jóvenes buscan acceso a Internet para ocupar su tiempo. 
Nivel de riesgo frente al consumo de drogas y la delincuencia de los jóvenes. El $85 \%$ de los padres encuestados afirmó que los adolescentes o jóvenes sí presentan riesgo de consumo de drogas y el otro $15 \%$ considera que no existe riesgo frente al consumo de drogas.

Tipos de riesgo. El $88 \%$ de los entrevistados del barrio San Luis y Buenos Aires II de Barrancabermeja identificó que el consumo de drogas es el mayor riesgo que tienen los jóvenes/adolescentes del sector, lo cual da indicio de que existen factores externos que han sido detectados por la misma comunidad y que se consideran una amenaza para determinar el rumbo del consumo temprano de drogas adictivas en los jóvenes/adolescentes de esta localidad.

Presencia de consumo de drogas en el barrio. El $65 \%$ de los entrevistados en el estudio consideró que actualmente el consumo de drogas como el cigarrillo y alcohol es significativo entre los jóvenes o adolescentes del barrio, por lo cual se puede concluir que los jóvenes del sector son propensos a caer en el consumo de drogas ilegales para experimentar mayores sensaciones que las actuales. Tan solo el $35 \%$ estimó que las drogas legales como el alcohol y cigarrillo no son consumidas por los jóvenes/ adolescentes de su sector.

Tipo de droga que se consume en el barrio. El $60 \%$ de los entrevistados afirmó que el consumo permanente de marihuana y perico es el mayor problema de muchos de los jóvenes del sector. Solo el $40 \%$ de los entrevistados señaló que no existe consumo de drogas ilegales en el barrio.

Estos resultados muestran que los adolescentes o jóvenes de los barrios San Luis y Buenos Aires II de Barrancabermeja se encuentran en situación de riesgo frente al consumo de drogas y la delincuencia juvenil, debido a su realidad sociocultural, económica y factores contextuales que hacen fácil la adquisición, compra y consumo de drogas y el desarrollo de conductas delictivas, debido a componentes asociados con la cultura de la ilegalidad propia de muchos sectores populares, en los que se mantienen representaciones sociales de que todo se puede y todo se vale, que los fines (escolar, económico y social) justifican los medios.

Otros resultados están relacionados con las acciones que se desarrollaron en el programa educativo, el cual se implementó durante un año en dos barrios de Barrancabermeja de estrato socioeconómico uno, ubicados en la comuna uno. Entre las principales acciones están:

I. Doscientas cincuenta (250) visitas domiciliarias del total de los 350 hogares que conformaban los dos barrios seleccionados para el proyecto. Los 100 hogares que no se visitaron. Fue porque no firmaron el consentimiento informado, es decir no mostraron interés explícito de querer participar en el proceso investigativo. Las visitas tuvieron una duración de 90 minutos, durante las cuales se explicaron los objetivos del proyecto, se aplicó la entrevista semiestructurada y se firmó el consentimiento informado.

2. Organización de 5 clubes juveniles, cada uno constituido por 20 jóvenes; tres en el barrio San Luis y 2 en el barrio Buenos Aires II. Los clubes se identificaron con un nombre, una mascota, construyeron un logo, una bandera, igualmente cada club eligió su junta, finalmente elaboraron planes de trabajo mensual con tareas semanales, que cumplieron en un $100 \%$.

3. 36 talleres experienciales con sus respectivas temáticas. Al total de las actividades asistió el $80 \%$ de los adolescentes o jóvenes inscritos inicialmente.

4. 12 actividades de réplicas, 7 en el barrio San Luis y 5 en el barrio Buenos Aires II. Las mismas consistieron en una visita domiciliaria a cada hogar para conocer su realidad; dos cineforos, dos brigadas de aseo y salud, dos obras de teatro con mensajes de protección frente al consumo de drogas y la delincuencia juvenil, tres actividades deportivas $y$ culturales donde se reforzaban valores de convivencia y una asamblea de socialización de resultados.

5. 10 experiencias vivenciales en las que se integró y puso a prueba lo aprendido en los 5 clubes juveniles. Estas experiencias de competencia se realizaron una vez al mes en el parque recreacional de la Caja de Compensación Familiar de Barrancabermeja "Cafaba", y las mismas posibilitaron aprender habilidades para la vida, a través de retos o desafíos que exigían poner en práctica una habilidad para resolver el desafío planteado.

6. Graduación de 80 adolescentes o jóvenes del programa, los cuales demostraron compromiso, constancia y cumplimiento de los objetivos del programa.

Respecto a los efectos del programa en los adolescentes o jóvenes que participaron es factible decir que el programa influyó positivamente en el proyecto de vida personal, familiar y comunitario de los 80 jóvenes que terminaron el programa y a su núcleo familiar, constituido aproximadamente por 320 personas. Específicamente el programa impactó de la siguiente manera:

I. Desarrolló habilidades para la vida y competencias prelaborales en adolescentes 0 jóvenes que participaron en el programa. Esto se evidenció en el hecho de que cuando iniciaron los 
adolescentes o jóvenes en el programa, es decir, en los dos primeros meses se observaban inseguros, introvertidos, poco comunicativos, aislados y sin habilidades para comunicarse asertivamente $y$ trabajar en equipo. Muchos tenían comportamientos agresivos y no seguían instrucciones. Después de dos meses de trabajo en los clubes juveniles se observó el surgimiento de valores, el desarrollo de habilidades para la vida y competencias prelaborales. Los talleres y las experiencias vivenciales les posibilitaron a los adolescentes o jóvenes poner en práctica habilidades o competencias como: cumplir un horario y un plan de trabajo, seguir y dar instrucciones, mantener una motivación intrínseca, comunicarse asertivamente, resolver problemas, tener empatía, trabajar en equipo y tener control de las emociones y del estrés, entre otras habilidades.

2. Permitió la construcción de tejido social e incrementó el sentido de pertenencia y adhesión con el barrio y la comunidad. Reflejado en reconocimientos mutuos, en ayuda recíproca, en acciones de solidaridad entre los adolescentes, jóvenes y adultos del barrio y en la capacidad de solucionar los problemas de manera pacífica.

3. Posibilitó la sensibilización, toma de consciencia y compromiso frente a las problemáticas cotidianas en el plano familiar y comunitario. Esto se evidenció en el hecho de que surgieron varias iniciativas individuales y grupales para solucionar problemas familiares y sociales como violencia intrafamiliar, recolección de basuras, conexión de servicios públicos y transporte.

4. Facilitó la organización, fortalecimiento y empoderamiento de los adolescentes o jóvenes frente a las dinámicas, realidades y problemas cotidianos de la comunidad. Lo que se observó en la capacidad de liderazgo y trabajo en equipo que mostraron los participantes en el programa durante el año que se desarrolló el proyecto, y llevó a que muchos de estos jóvenes lideraran ideas como las de ser vigías de la salud, formar parte del comité de alertas tempranas, comités culturales y deportivos, formar parte de la junta de acción comunal del barrio, servir de enlace entre la comunidad y la Policía Nacional, la Personería Municipal y la Defensoría del Pueblo como garantes de la seguridad y derechos de la comunidad.

5. Logró que los adolescentes o jóvenes que participaron en el programa se reconocieran como sujetos de deberes y derechos en el ejercicio de la ciudadanía. Esto se reflejó en el hecho de que aprendieron a implicarse en los problemas y a formar parte de su solución. Igual aprendieron a ser asertivos en la comunicación y en la solución de problemas. Se observó que por lo menos el $60 \%$ de los adolescentes o jóvenes aprendieron a manejar sus emociones y dejaron de ser impulsivos, reactivos, para ser más reflexivos y propositivos.

6. Permitió la construcción de un entorno comunitario saludable. Los jóvenes y los padres de familia empezaron a preocuparse más por contrarrestar los factores de riesgo que los hacían vulnerables, aprendieron a tener conductas de autocuidado y a identificar y evitar situaciones de riesgo; desarrollaron hábitos de vida saludable.

7. Posibilitó la construcción de alertas tempranas frente a los riesgos asociados al consumo de drogas y delincuencia juvenil. Cada barrio construyó con el acompañamiento de la junta de acción comunal, la policía y la Personería Municipal sus estrategias de alerta temprana de riesgo de consumo de drogas y delincuencia juvenil.

8. Hubo transformación de hábitos de vida que ponían en riesgo la dignidad humana, la salud física y psicológica, y el desarrollo económico y social. Los adolescentes o jóvenes aprendieron a invertir su tiempo libre en actividades más productivas de orden formativo, cultural y deportivo, este impacto se evidenció en la organización de 2 comités deportivos y culturales, $y$ en el hecho de que los 10 adolescentes o jóvenes que estaban por fuera del sistema educativo retomaron su educación formal.

\section{Discusión}

En la aplicación del programa "Clubes juveniles, una estrategia de aprendizaje experiencial para la prevención del consumo de drogas y delincuencia juvenil" se pudo comprobar que la educación experiencial basada en actividades prácticas logra enganchar más a los adolescentes o jóvenes que los tradicionales programas preventivos basados solo en información y en estilos de aprendizaje que no involucran todos los sentidos, como lo argumenta en su trabajo Malagón (2 107). Igualmente, el desarrollo del programa evidenció que los jóvenes aprenden más y dicho aprendizaje dura más, cuando se involucran acciones $u$ actividades previamente planificadas para ser desarrolladas partiendo de la experiencia concreta, pasando por observación reflexiva de la actividad, para después conceptualizar sobre lo que se va hacer y terminar con la ejecución de la actividad o experiencia (aprender haciendo) (Kolb et al., 200 I). No hay duda de que los clubes juveniles son una estrategia de enseñanza que permite poner en práctica los planteamientos del aprendizaje experiencial, y en ese sentido, logra un mayor nivel de motivación 
por parte de los adolescentes o jóvenes frente a los aprendizajes propuestos, como bien lo ha asumido el ICBF (20II).

Con relación al desarrollo de habilidades para la vida, la ejecución del programa demostró que el mismo es efectivo para la prevención del consumo de drogas y la delincuencia juvenil, en tanto desarrolló competencias o capacidades para la toma de decisiones asertivas, el autocuidado y la identificación y protección frente al riesgo, como lo constatan otras investigaciones, entre las que están la de la OPS (200 I) y la de Mantilla (200I), quien, a partir del trabajo de la Fundación Fe y Alegría llegó a la conclusión de que las habilidades son efectivas para habilitar a los jóvenes para la vida y para prevenir todo tipo de riesgos, entre ellos el del consumo de drogas y la delincuencia juvenil.

En específico, el conocimiento de sí mismo, la empatía, la comunicación efectiva, las relaciones interpersonales, la toma de decisiones, la solución de problemas y conflictos, el pensamiento creativo, el pensamiento crítico, el manejo de sentimientos y el manejo de las tensiones conducen a un adolescente o joven a la construcción de un auténtico proyecto de vida, alejado de los problemas y en marcado en la posibilidad de ser feliz de manera plena e integral (Mantilla, 200I).

Este trabajo al igual que los citados en Pérez (20I2) son evidencia científica de que el aprendizaje vivencial y las habilidades para la vida son la mejor herramienta para prevenir, disminuir, decrementar o erradicar el consumo de drogas y la delincuencia en los jóvenes de contextos vulnerables. Una problemática que asecha a gran parte de nuestra juventud que fuera de tener que lidiar con la pobreza, la marginalidad y la exclusión debe hacer frente al flagelo del consumo de drogas que trae daños asociados o efectos colaterales de orden personal, familiar y social como la delincuencia juvenil.

La implementación de la estrategia educativa, el club juvenil, puso en evidencia las cuatro etapas del aprendizaje vivencial, como lo planteó en su tiempo Kolb et al. (200I). Experimentación activa; experiencia concreta; observación reflexiva y conceptualización abstracta. Las actividades implementadas en los clubes, los talleres experienciales y la experiencia vivencial o desafíos se organizaron teniendo en cuenta esa secuencia, lo que les posibilitó a los adolescentes o jóvenes partir de la presentación de un caso de la vida real, que exigía el desarrollo de acciones para solucionar o resolverlo, y posteriormente se reflexionaba sobre lo hecho (metacognición). La actividad se terminaba con un análisis y exteriorización o expresión de cómo estuvo el desempeño de cada uno, en qué fallaron, qué estuvo bien, qué había por mejorar, qué les funcionó mejor a los otros grupos, etc. Este paradigma lleva a que de manera motivada el adolescente o joven ponga en práctica lo aprendido y hace visible las habilidades o capacidades que se requieren en la vida cotidiana para llegar a tener éxito o alcanzar metas.

\section{Referencias}

Bonilla, E., \& Rodríguez, P. (1997). Más allá del dilema de los métodos: la investigación en ciencias sociales. Norma.

Castro, M., Llanes, J., \& Margain, M. (1999). Modelo preventivo de riesgos psicosociales para menores adolescentes y sus familias. Inepar, A. C.

Chaparro, J. (2015, 10 de agosto). Diagnóstico ambiental de Barrancabermeja (Santander). http://blogjbarahona.blogspot.com/2015/08/ area-barrancabermeja-esuna-ciudad.html

Díaz, M., \& Mejía, S. (20I8). Desarrollo de habilidades para la vida en la prevención del consumo de sustancias psicoactivas: un enfoque crítico al modelo existente. El Ágora USB, I8(I), 203210.0

Fondo de las Naciones Unidas para la Infancia [Unicef]. (2017). Habilidades para la vida. Herramientas para el buen trato y la prevención de la violencia. UNICEF, I-II. https://www.unicef. org/venezuela/media/43I/file/Habilidades $\% 20$ para $\% 201$ a $\% 20$ vida. $\% 20$ Herramientas $\% 20$ para\%20el\%20\#BuenTrato\%20y\%20la\%20 prevenci\%C3\%B3n\%20de\%20la\%20violencia. pdf

Fundación Jacobs. (201I). Directrices Fundación Jacobs sobre seguimiento y evaluación de las habilidades para la vida orientadas al desarrollo de la juventud. Volumen I. Fundación Jacobs. http://docplayer.es/71741991-Seguimientoy-evaluacion-de-las-habilidades-para-la-vidaorientadas-al-desarrollo-de-la-juventudvolumen-I-directrices.html

Fundación Reeducativa Profuturo. (2014). Prevalencia del consumo de drogas y factores de riesgo y protección en estudiantes de colegios de Barrancabermeja. Informe final de investigación Fundación Reeducativa Profuturo, I-I 20.

Gómez, J. (20lI). El aprendizaje experiencial. Universidad de Buenos Aires, Facultad de Psicología, I-2I. http://www.ecominga.uqam.ca/ ECOMINGA_20II/PDF/BIBLIOGRAPHIE/ GUIDE_LECTURE_5/I/3.Gomez_Pawelek.pdf

Instituto Colombiano de Bienestar Familiar [ICBF]. (20II). Programa de clubes pre y juveniles. Documento Técnico Instituto de Bienestar Familiar, I-18. https://www.icbf.gov.co/sites/ default/files/anexolfichadecondiciones.pdf 
Instituto Nacional sobre Abuso de Drogas en estados Unidos -NIDA. (2004). Como Prevenir el uso de drogas en los niños y adolescentes. Una guía con base científica para educadores, padres de familia y lideres de la comunidad. NIDA. https://www.drugabuse.gov/es/ publicaciones/como-prevenir-el-uso-dedrogas/reconocimientos

Kolb, D. A., Boyatzis, R. E., \& Mainemelis, C. (200I). Experiential learning theory: previous research and new directions. En R. J. Sternberg \& L. Zhang (eds.), The Educational Psychology Series. Perspectives on Thinking, Learning, and Cognitive Styles (pp. 227-247). Lawrence Erlbaum Associates Publishers.

López, M. (2003). Construye tu vida sin adicciones. Secretaria de Salud de México, I-45. http://bases.bireme.br/cgi-bin/wxislind. exe/iah/online/? IsisScript=iah/iah. xis \&src = google\&base $=$ LILACS\&lang $=$ $p \&$ nextAction $=$ Ink\&exprSearch $=275702$ \&indexSearch $=$ ID

Malagón, J. (2017). Clubes de talento joven, una propuesta pedagógica para promover la inteligencia social. Universidad Complutense de Madrid, 67-84. http://www.injuve.es/ sites/default/files/20 I 8/23/publicaciones/ documentos_4._clubes_de_talento_ joven_II7.pdf

Mantilla, L. (200I). Habilidades para la vida. Una propuesta educativa para la promoción del desarrollo humano y la prevención de problemas psicosociales. Fe y Alegría, I-27. www.codajic.org/sites/default/files/sites/ www.codajic.org/files/Habilidades $\% 20$ para\%20la\%20vida\%20.\%20Leonardo\%20 Mantilla\%20Castellanos..pdf

Ministerio de Educación Nacional de Colombia. (2020). Informe al Congreso. Junio de 2019. mayo de 2020. https://www.mineducacion. gov.co/I759/articles-385377_recurso_I4.pdf
Ministerio de Justicia y Oficina de las Naciones Unidas contra la Droga y el Delito [UNODC]. (2015). Atlas de la caracterización regional de la problemática asociada a las drogas ilícitas en el departamento de Santander, I-26. http:// www.odc.gov.co/portals/I/regionalizacion/ caracterizacion/RE0620I5-caracterizacionregional-problematica-asociada-drogasilicitas-santander.pdf

Molina, L. (2008) Barrancabermeja: segregación socio espacial y desequilibrios funcionales. Cuaderno de Vivienda y Urbanismo Universidad Javeriana, I(2), 332-346.

Organización Panamericana de la Salud [OPS]. (200I). Enfoque de habilidades para la vida para un desarrollo saludable de niños y adolescentes. OPS. http://www.codajic.org/sites/default/ files/sites/www.codajic.org/files/Enfoque $\% 20$ de\%20Habilidades\%20para\%20la\%20vida\%20 OPS_0.pdf

Otero, D. (20I5) Historia de la Fundación de Barrancabermeja y el papel del petróleo. Uniciencia.

Pérez, C. (20I2). Habilidades para la vida y consumo de drogas en adolescentes escolarizados mexicanos. Revista Adicciones Sociedad Científica Española de Estudios sobre el Alcohol, el Alcoholismo y las otras Toxicomanías, 24(2), I53-160.

Pick, S: Leenen, I; Givaudan, M., \& Prado, A. (2010). "Yo quiero, yo puedo... prevenir la violencia": Programa breve de sensibilización sobre violencia en el noviazgo. Salud Mental, 33(2), I53-160.

Stake, R. (1999). Investigación con estudio de caso. Morata.

Taylor, S. J., \& Bogdan, R. (1992). Introducción a los métodos cualitativos en investigación. La búsqueda de los significados. Paidós. 


\section{Apéndice}

\section{Consentimiento informado para la participación en los clubes juveniles}

Barrancabermeja de de 20

Usted y su núcleo familiar tienen derecho a conocer los objetivos del programa del que va hacer parte su hijo(a), este documento le explica todas estas cuestiones, léalo atentamente y consulte todas las dudas que se le planteen. Le recordamos que por exigencia legal, tendrá que firmar usted o su representante legal el consentimiento informado para que pueda ser partícipe del programa.

\section{Información suministrada y recomendaciones}

Se informa al adolescente y/o joven y a su tutor o representante legal los aspectos fundamentales del programa educativo. Igualmente, se les comunica el horario y tiempo que se debe dedicar al mismo y las fases que constituyen esta propuesta:

I. PRIMERA ETAPA: selección, inducción e inicio del programa de desarrollo de habilidades para la vida

Duración: 9 meses

Población beneficiaria: adolescentes y/o jóvenes de edades entre los 12 y 21 años de estrato 1 y 2 en riesgo frente al consumo de drogas y/o consumidores residentes del barrio San Luis.

A partir de la firma de convenio interinstitucional con la Junta de Acción Comunal se hará el censo que permita identificar el número de jóvenes potenciales para el programa, sus características y necesidades relacionadas con prevención de consumo de drogas, igualmente se hará una encuesta de interés de participación de los jóvenes en el programa. Se seleccionarán los jóvenes para el programa educativocomunitario teniendo en cuenta: el interés de participación, la firma del consentimiento informado de los padres, la disponibilidad de los padres de familia de los jóvenes para participar en las actividades educativas que se van a realizar con ellos, la entrega oportuna de documentación para la inscripción en el programa: formulario de inscripción, entrega de fotografía, fotocopia de tarjeta de identidad y fotocopia de sistema de salud a la cual está afiliado el joven.

Estrategia de intervención: organización y desarrollo de clubes juveniles, los cuales serán un espacio de encuentro y reconocimiento entre los jóvenes del barrio San Luis de la comuna I del municipio de Barrancabermeja, en edades entre los 12 y 21 años. Se organizarán 4 clubes con un promedio entre 10 y 12 años miembros y/o integrantes cada uno.

Estos clubes se reunirán cada ocho días en el parque Inscredial, estarán liderados por los jóvenes en edades entre los 18 y 21 años y guiados $u$ orientados por los profesionales de la Fundación. La idea es que organicen su estructura administrativa, elaboren estatutos de funcionamiento, establezcan roles y funciones al interior del club e igualmente construyan conjuntamente un plan de acción entorno al propósito de prevenir el consumo de drogas en los jóvenes del barrio, finalmente deben establecer una metodología de trabajo.

Los encuentros de cada 8 días tiene como propósito rendir cuentas o revisar el trabajo educativocomunitario desarrollado por los integrantes del club durante la semana en el barrio, igualmente la reunión semanal de los clubes juveniles tiene como propósito desarrollar actividades lúdico-recreativas, dinámicas grupales de integración y fortalecimiento del arraigo y sentido de pertenencia de los integrantes del club y finalmente en las reuniones semanales se organizarán competencias al aire libre, organizadas de tal manera que permitan el aprendizaje experiencial o vivencial de las habilidades para la vida mediante la competencia grupal.

II. SEGUNDA ETAPA: proyecto vocacional y ocupacional

\section{Duración: 6 meses}

Al finalizar el tercer mes de la primera etapa del programa, se evaluarán y seleccionarán los jóvenes en edades entre los 18 y 21 años con mayores factores de riesgo frente al consumo de drogas, la violencia y delincuencia juvenil o que se encuentren en etapa de inicio de consumo, para involucrarlos en una segunda etapa de formación relacionada con desarrollo de competencias ocupacionales y hábitos prelaborales. 
Los jóvenes seleccionados serán aquellos que demuestren mayor compromiso y entrega con el programa educativo de clubes juveniles, con estos jóvenes, un promedio de 20 entre hombres y mujeres, se iniciará una etapa de formación que les posibilitará emprender su proyecto vocacional y ocupacional.

Paralelo a esta formación, los 20 jóvenes seleccionados seguirán participando y liderando los clubes juveniles y el trabajo educativo comunitario para la prevención de consumo de drogas, violencia y delincuencia juvenil que se adelanta en su barrio.

Población beneficiaria: jóvenes de edades entre los 18 y 21 años de estrato 1 y 2 en riesgo frente al consumo de drogas y/o consumidores, violencia $y$ delincuencia juvenil.

Estrategia de intervención: actividades experienciales de formación vocacional y ocupacional, esta formación se dividirá en tres niveles así: proyecto de vida, orientación vocacional y desarrollo de hábitos prelaborales.

Metodología: formación para la vida y el trabajo, a través de la enseñanza teórico-práctica se busca iniciar el desarrollo del proyecto de vida ocupacional de estos jóvenes, orientarlos en sus preferencias vocacionales u ocupacionales y desarrollar hábitos prelaborales. La idea es que los jóvenes en condición de vulnerabilidad completen el ciclo de formación que busca prevenir y/o alejarlos del consumo de drogas, la violencia y la delincuencia. El programa busca la formación para la vida, para la convivencia social y para el trabajo.

Los jóvenes asistirán a las instalaciones de la Fundación para recibir su formación tres veces por semana, en horario contrario a sus actividades académicas u ocupacionales habituales.

III. TERCERA ETAPA: sensibilización a la comunidad con relación al trabajo de prevención y rehabilitación de la drogodependencia

\section{Duración: 2 meses}

Uno de los impactos que busca el desarrollo de este trabajo es el de sensibilizar a la comunidad de Barrancabermeja en general y a los empresarios en particular en la importancia de prevenir e intervenir a tiempo a los adolescentes y/o jóvenes de sectores populares y/o marginados para que no caigan en el consumo de drogas, en comportamientos violentos y la delincuencia. La importancia de formar para la vida y desarrollar habilidades y competencias ocupacionales que alejen a los jóvenes de las situaciones de riesgo propias de su contexto; en ese sentido, la tercera etapa de este programa es la de divulgar los resultados del trabajo educativo comunitario.

Dirigido a: empresarios, organizaciones gubernamentales y no gubernamentales, centros educativos y medios de comunicación.

Estrategia de intervención: correspondencia, visitas, desarrollo de seminario y evento social. Lo que se busca es presentar a la comunidad en general el programa de prevención y atención al problema de la drogadicción, violencia y delincuencia de los jóvenes en el municipio; $y$ sensibilizar a la comunidad sobre la necesidad de prevenir e intervenir el consumo de droga con el propósito de disminuir los índices de violencia y delincuencia en nuestra ciudad. lgualmente concientizar sobre la necesidad de apoyar a nuestros adolescentes y jóvenes en la construcción de proyectos de vida libres de droga.

\section{Riesgos que representa el programa}

Los riesgos a nivel de salud física y psicológica a los que se enfrenta el participante en el programa son mínimos, en tanto el participante no será sometido a actividades que impliquen ningún tipo de riesgo físico o psicológico, ni a procedimientos médicos ni psicológicos complejos. Así mismo, su participación en las actividades individuales y grupales serán voluntarias de acuerdo con la comodidad y tranquilidad que sienta el participante en las mismas.

\section{Declaración de consentimiento informado}

\begin{tabular}{ll} 
El/la que suscribe & \\
\hline ciudadanía $\mathrm{N}^{\circ}$ & $\begin{array}{l}\text { con cédula de } \\
\text { en con domicilio } \\
\text { mi consentimiento para que mi hijo(a) }\end{array}$ \\
\hline CC/T.I $\mathrm{N}^{\circ}$ & $\begin{array}{r}\text { con } \\
\text { inicie }\end{array}$
\end{tabular} el programa educativo comunitario de desarrollo de habilidades para la vida y hábitos prelaborales desarrollado por la Fundación Reeducativa Profuturo apoyado en su equipo interdisciplinario. 
A propósito declaro haber sido informado(a) y haber comprendido acabadamente que el objeto del programa es la formación en valores, el desarrollo de habilidades para la vidala y de hábitos prelaborales.

He leído las instrucciones del programa educativocomunitario que me ha entregado el director científico de la Fundación Reeducativa Profuturo, el Dr. Armando Aguilera Torrado y he comprendido todas las explicaciones que se me han facilitado en lenguaje claro y sencillo, he podido realizar todas las observaciones y se me han aclarado todas las dudas, por lo que estoy completamente de acuerdo con lo consignado en este documento de consentimiento.

Asimismo, entiendo que el programa educativo comunitario está constituido por tres fases y que el mismo solo concluye una vez terminada las tres fases, a fin de lograr el objetivo general del programa, por lo que me comprometo a asistir a las actividades individuales y grupales que constituyen el programa durante el tiempo requerido para cumplir con las tres fases ( 9 meses).

Firma del representante legal o tutor

Firma del director científico de la Fundación

Firma del participante en el programa 